\title{
Rearrangements versus Ligand Exchange Reactions of Organocobalt Polymer Having Cobaltacyclopentadiene Moieties in the Main Chain ¥
}

\author{
Ikuyoshi Tomita, $†$ Akinori Nishio and Takeshi Endo* \\ Research Laboratory of Resources Utilization, Tokyo Institute of Technology, Nagatsuta, Midori-ku, \\ Yokohama 226-8503, Japan
}

The rearrangement reaction of an organocobalt polymer with cobaltacyclopentadiene moieties in the main chain (1) was carried out to yield a new polymer bearing ( $\eta^{5}$-cyclopentadienyl) $\left(\eta^{4}\right.$ cyclobutadiene)cobalt moieties in the main chain (2). For instance, a polymer (2) containing pure $\eta^{4}$-cyclobutadienecobalt units was obtained as a yellow powder in $79 \%$ yield by the reaction of 1 in tetrahydrofuran (THF) at $110{ }^{\circ} \mathrm{C}$ for $1 \mathrm{~h}$ in a sealed tube. The polymer (2) obtained was soluble in organic solvents such as chloroform, THF and $N, N$-dimethylformamide and was quite stable under air. It showed good thermal stability and a weight loss of $5 \%$ was observed at $482{ }^{\circ} \mathrm{C}$ by thermogravimetric analysis (TGA). On the other hand, displacement of the triphenylphosphine ligands on the main chain of the organocobalt polymer (1), without rearrangement of the cobaltacyclopentadiene rings, was observed when the reaction was carried out in the presence of appropriate ligands such as $\mathbf{P}(\mathbf{n}-$ $\mathrm{Bu})_{3}$. The resulting ligand-exchanged polymer showed different properties in comparison with 1. For instance a polymer bearing tri-n-octylphosphine is soluble in n-hexane, which is a poor solvent for 1. (C) 1998 John Wiley \& Sons, Ltd.

Keywords: polymer; organocobalt

\footnotetext{
* Correspondence to: Takeshi Endo, Research Laboratory of Resources Utilization, Tokyo Institute of Technology, Nagatsuta, Midori-ku, Yokohama 226-8503, Japan.

$\dagger$ Current address: Department of Electronic Chemistry, Interdisciplinary Graduate School of Science and Engineering, Tokyo Institute of Technology, Nagatsuta, Midori-ku, Yokohama 2268502, Japan.

\$ Part of the work presented here was communicated in Ref. 1 . Contract/grant sponsor: Ministry of Education, Science and Culture, Japan.

Contract/grant sponsor: Grant-in-Aid for Scientific Research on the Priority Area of Reactive Organometallics; Contract/grant number: 05236104 .
}

Received 14 May 1997; accepted 4 June 1997

\section{INTRODUCTION}

Organometallic systems are interesting building blocks for the synthesis of polymeric materials with specified reactivities and functions. By incorporation of the organometallic system into the main chain of the polymer, new type of reactive polymers that have reactive points in the main chain might be produced. Recently, we have described the synthesis of organocobalt polymers (1) with cobaltacyclopentadiene moieties in the main chain, by oxidative coupling (i.e. oxidative ring closure) of diynes with a ( $\eta^{5}$-cyclopentadienyl)bis(triphenylphosphine)cobalt complex (Scheme 1). ${ }^{2,3}$ The number-average molecular weights $\left(M_{\mathrm{n}}\right)$ of $\mathbf{1}$ were quite sensitive to the purity of the organometallic monomer; $M_{\mathrm{n}}$ values of up to 200000 have been reached by using a purified cobalt monomer. Synthesis of similar types of organometallic polymers have been reported. ${ }^{4-7}$

The organocobalt polymers (1) obtained were successfully converted to 2-pyridone-containing polymers by reaction with isocyanates (Scheme 2). ${ }^{8}$ The result clearly demonstrates that polymers with appropriate organometallic systems in the main chain serve as reactive polymers that can produce novel polymers whose structures might be difficult to construct by the other methods.

Besides the applications of organocobalt polymers (1) as precursors for organic polymers, interesting reactions that convert $\mathbf{1}$ to organocobalt polymers having different skeletons might be possible on the basis of the reactivity of cobaltacyclopentadienes. A thermal rearrangement reaction of derivatives of cobaltacyclopentadiene has 


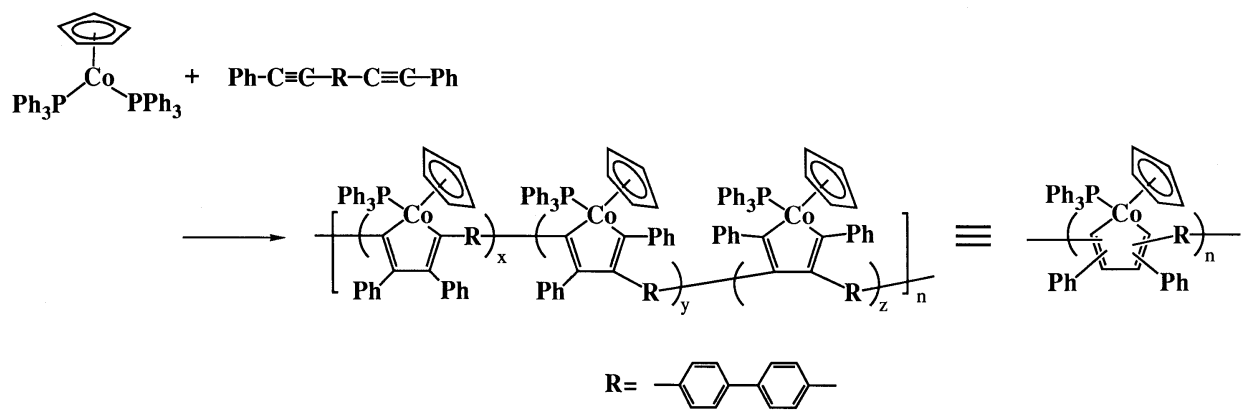

Scheme 1

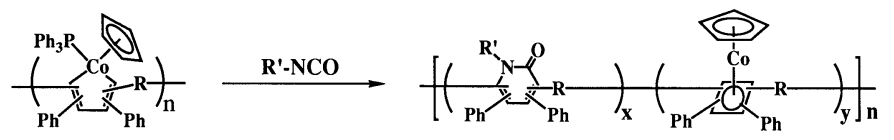

Scheme 2

been reported to take place to provide the corresponding derivatives of $\left(\eta^{4}\right.$-cyclobutadiene)cobalt above its melting temperature. ${ }^{9}$ The resulting cyclobutadienecobalt compounds are known to be quite stable, since they are isoelectronic with ferrocene. ${ }^{10}$ Because polymers containing cyclobutadienecobalt repeat units may serve as novel materials with higher stability, a rearrangement of the organocobalt polymer was examined here. Generally, ligands on the metal atom can be simply displaced by the appropriate ligands. Accordingly, the rearrangement might be prohibited in the presence of ligands with better coordination abilities, by which the side-chain of the polymer might be modified without involving rearrangement of the polymer backbone. Thus, the reaction was also carried out in the presence of appropriate ligands.

\section{RESULTS AND DISCUSSION}

\section{Thermal rearrangement reaction}

As mentioned above, the thermal rearrangement reaction of derivatives of cobaltacyclopentadiene has been reported to take place above its melting point $\left(193-194{ }^{\circ} \mathrm{C}\right)$ to produce the corresponding derivatives of $\left(\eta^{4}\right.$-cyclobutadiene) cobalt in $60 \%$ yield. ${ }^{9}$ In the case of the organocobalt polymer $\mathbf{1}$, the weight loss presumably originating from the

(C) 1998 John Wiley \& Sons, Ltd. corresponding rearrangement was observed above $197^{\circ} \mathrm{C}$ by thermogravimetric analysis (TGA; vide infra). ${ }^{2,3}$ After the polymer had been annealed at $250{ }^{\circ} \mathrm{C}$ it was, however, barely soluble in organic solvents which made its structure difficult to characterize. To overcome this problem, the reaction was carried out in a tetrahydrofuran (THF) solution. [When the sample was washed with $\mathrm{CH}_{2} \mathrm{Cl}_{2}$ after annealing at $250{ }^{\circ} \mathrm{C}$ triphenylphosphine was detected, which indicates that the rearrangement reaction also took place in the bulk. The formation of less-soluble materials as well as the lower yield in the case of the model reaction in the crystalline state ( $\mathrm{ca}$ 60\%) might be due to intermolecular side-reactions caused by the coordinatively unsaturated cobalt, which may potentially coordinate to the unsaturated bonds of other organometallic systems under very high concentration.]

The reaction of a brown organocobalt polymer $\left(\mathbf{1}, M_{\mathrm{n}}=35100\right)$ prepared by the reaction of $\left(\eta^{5}-\right.$ cyclopentadienyl)bis(triphenylphosphine)cobalt with 4,4'-bis(phenylethynyl)biphenyl was carried out at $110^{\circ} \mathrm{C}$ in THF in a sealed tube without any added reagents. After reaction for $1 \mathrm{~h}$, the solution turned yellow but nothing was precipitated from it throughout the reaction. By precipitation of the resulting solution with n-hexane, a yellow powdery polymer (2) was obtained in $79 \%$ yield (Scheme 3 ). The polymer $\mathbf{2}$ is completely soluble in organic solvents such as THF, chloroform and N,N- 


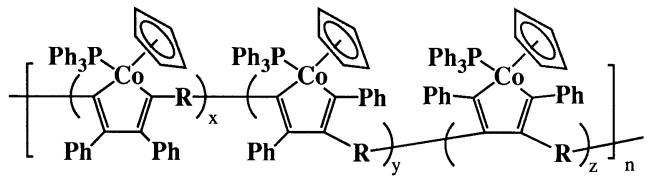

1

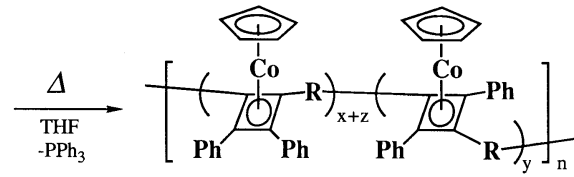

$\underline{2}$

Scheme 3

dimethylformamide, and its $M_{\mathrm{n}}$ was estimated as 33 200 by GPC on the basis of standard polystyrene samples. Although GPC measurement is not a precise method for the direct comparison of the molecular weights between $\mathbf{1}$ and $\mathbf{2}$, the similarity in the molecular weights of samples before and after the reaction may support the idea that any side reactions (such as a cleavage of the main chain or a crosslinking reaction) did not take place during the reaction. From the n-hexane-soluble fraction obtained from the precipitation process, triphenylphosphine that had been eliminated was detected, accompanied by triphenylphosphine oxide.

The quantitative conversion of $\mathbf{1}$ to the polymer $\mathbf{2}$ was supported by the model reaction of $\mathbf{3}$ under the same conditions. In this case, a derivative of $\left(\eta^{5}\right.$-cyclopentadienyl $)\left(\eta^{4}\right.$-cyclobutadiene $)$ cobalt (4) was isolated in $97 \%$ yield by column chromatography (Scheme 4). Further, the structure of 2 was confirmed by ${ }^{1} \mathrm{H},{ }^{13} \mathrm{C}$ and ${ }^{31} \mathrm{P} \mathrm{NMR}$, and $\mathrm{IR}$ analyses. In the ${ }^{1} \mathrm{H}$ NMR spectrum of 2 (Fig. 1b), a peak attributable to cyclopentadienyl moieties was observed at 4.66 ppm similarly to the case of 4 (Fig. 1c), while the corresponding peak in $\mathbf{1}$ appeared at $4.76 \mathrm{ppm}$ (Fig. 1a). The integral ratio of the peaks in the aromatic region and that of the cyclopentadienyl group also supported the complete conversion to 2 . In the ${ }^{13} \mathrm{C}$ NMR spectrum of 2 , the cyclopentadienyl group was detected at $83.29 \mathrm{ppm}$, which is very close to the corresponding peak in $\mathbf{4}$ $(83.24 \mathrm{ppm})$. No peak for the starting unit in $\mathbf{1}$ was observed at $89.70 \mathrm{ppm}^{2,3}$ As expected, no peak was detected in the ${ }^{31} \mathrm{P}$ NMR spectrum of 2.

This reaction could be monitored by the measurement of the ${ }^{1} \mathrm{H}$ NMR spectra by comparing the integral ratio of the peaks at 4.66 and $4.76 \mathrm{ppm}$ (i.e. the cyclobutadienecobalt and cobaltacyclopentadiene units, respectively). As shown in Table 1, reaction for $50 \mathrm{~min}$ was sufficient for complete conversion to $\mathbf{2}$ at $110^{\circ} \mathrm{C}$.

The thermal stability of $\mathbf{2}$ was estimated by thermogravimetric analysis (TGA) under nitrogen (Fig. 2). No weight loss was observed below $400^{\circ} \mathrm{C}$ and the temperature for $5 \%$ weight loss $\left(T \mathrm{~d}_{5}\right)$ was $482^{\circ} \mathrm{C}$, which was much higher than that of $\mathbf{1}$. From the differential scanning calorimetric analysis (DSC) of 2, no peak attributable to the glass temperature $\left(T_{\mathrm{g}}\right)$ or the melting point $\left(T_{\mathrm{m}}\right)$ was observed below the decomposition temperature.

The reaction may proceed via the initial dissociation of triphenylphosphine ligand on the cobalt atom. The resulting coordinatively unsaturated cobaltacyclopentadiene units may undergo a rearrangement to form cyclobutadienecobalt moieties.

\section{Displacement of the ligand on the organocobalt polymer}

In the presence of appropriate ligands with better coordination abilities, the triphenylphosphine on the cobalt atom might be simply replaced by the added ligands, i.e. the side-chain of the organocobalt polymer might be modified. This kind of displacement of the ligand on the cobaltacyclopentadiene derivative has been reported in the case of the reaction with trialkylphosphite, ${ }^{11}$ which, however, involved the rearrangement of the metallacycle to produce derivatives of phosphole oxide. For the simple ligand-exchange reaction, trialkyl-

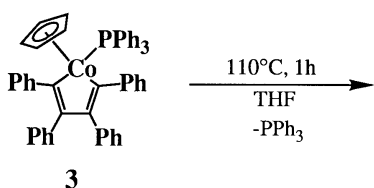

$\underline{\mathbf{3}}$

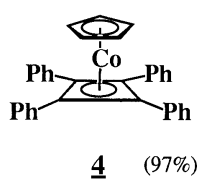

$4 \quad(97 \%)$

Scheme 4 
(a)
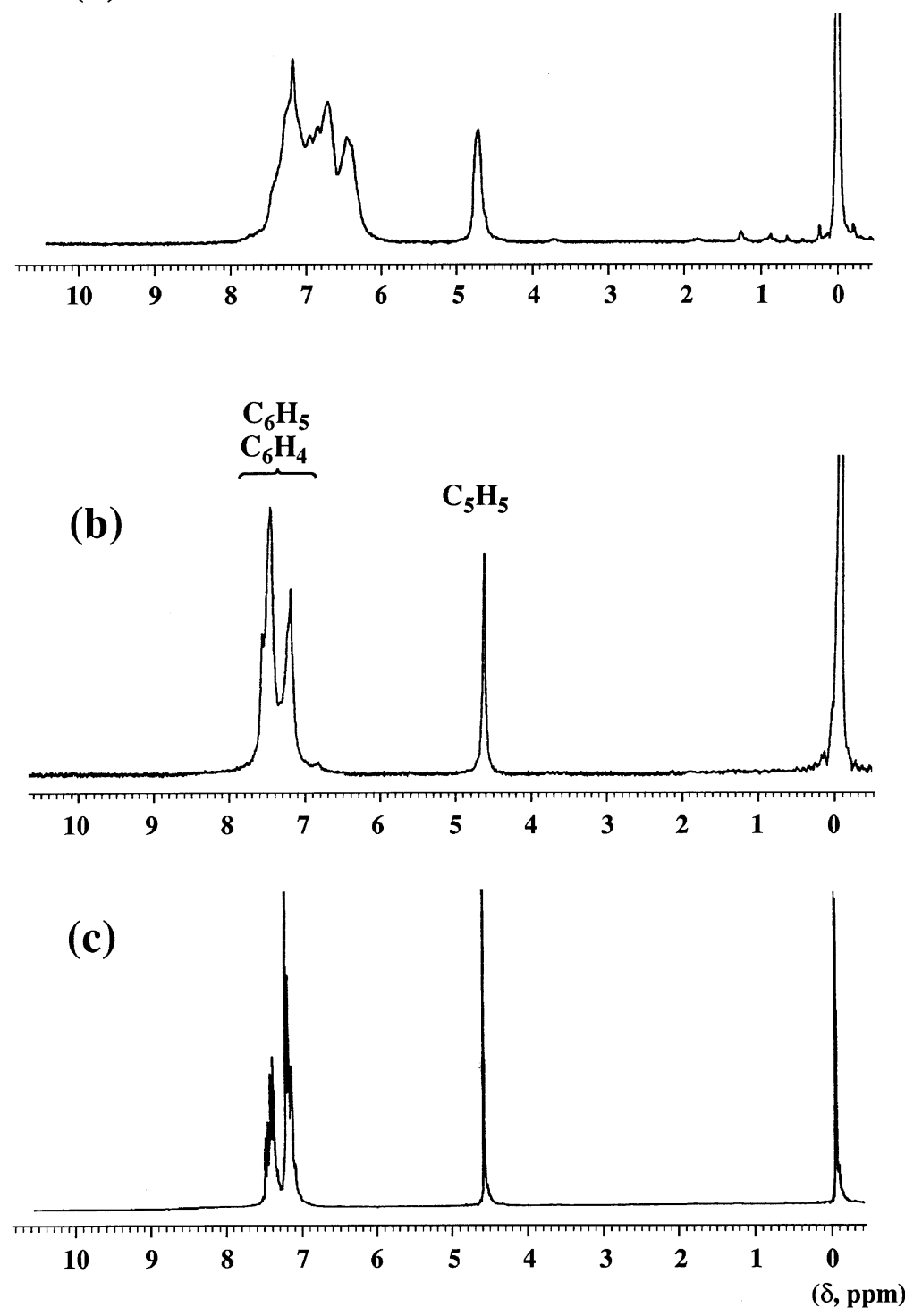

Figure $1{ }^{1} \mathrm{H}$ NMR spectra $\left(90 \mathrm{MHz}\right.$, in $\left.\mathrm{CDCl}_{3}\right)$ of $\mathbf{1}$ (a), 2 (b) and $\mathbf{4}$ (c).

phosphines might be suitable to be use instead of trialkylphosphites. Therefore a model reaction was carried out, using a derivative of cobaltacyclopentadiene (3) and tri-n-butylphosphine (5a) (Scheme 5 ; Table 2). By reaction of $\mathbf{3}$ with 1 equiv. of $\mathbf{5 a}$ in THF at $110^{\circ} \mathrm{C}$ for $1 \mathrm{~h}$ (i.e. under similar conditions to the above-mentioned rearrangement reaction), the cobaltacyclopentadiene (6a) bearing tri-nbutylphosphine as a ligand was isolated by column chromatography in 64\% yield, accompanied by 4

(C) 1998 John Wiley \& Sons, Ltd.
(33\%, run 1). By using 10 equiv. of 5a, the formation of 4 was suppressed and the isolated yield of $\mathbf{6 a}$ increased to $92 \%$ (run 2). On the other hand, the reaction did not take place at lower temperature $\left(<90^{\circ} \mathrm{C}\right)$ and the reaction at much higher temperatures (e.g. at $150^{\circ} \mathrm{C}$ ) resulted in rearrangement to produce 4 . Although $\mathbf{6 a}$ also underwent the rearrangement at higher temperatures (e.g. at $150^{\circ} \mathrm{C}$ ), $6 \mathbf{a}$ was a little more thermally stable at $110^{\circ} \mathrm{C}$ in comparison with 3 .

Appl. Organometal. Chem. 12, 735-742 (1998) 
Table 1 Conversion of 1 into $\mathbf{2}^{\mathrm{a}}$

\begin{tabular}{lcc}
\hline Run & $\begin{array}{c}\text { Reaction time } \\
\text { (min.) }\end{array}$ & $\begin{array}{c}\text { Ratio, cyclobutadienecobalt : } \\
\text { cobaltayclopentadiene } \\
\text { (units/units) }\end{array}$ \\
\hline 1 & 30 & $85: 15$ \\
2 & 45 & $90: 10$ \\
3 & 50 & $100: 0$
\end{tabular}

${ }^{\text {a }}$ Reaction of $1(0.050 \mathrm{~g})$ was carried out at $110^{\circ} \mathrm{C}$ in THF $(10 \mathrm{ml})$ in a sealed tube.

${ }^{b}$ Determined by ${ }^{1} \mathrm{H}$ NMR, based on the signal of the cyclopentadienyl moieties.

Because the displacement reaction was found to take place under appropriate conditions, the reaction of the organocobalt polymer $\left(1, M_{\mathrm{n}}=27000\right.$, $\left.M_{\mathrm{w}} / M_{\mathrm{n}}=1.5\right)$ was carried out with 10 equiv. of $\mathbf{5 a}$ in $\mathrm{THF}$ at $110^{\circ} \mathrm{C}$ for $1 \mathrm{~h}$ (Scheme 6). After the reaction, the reaction mixture was poured into excess n-hexane to precipitate a brown powdery polymer (7a) in $94 \%$ yield (the triphenylphosphine eliminated was detected in the n-hexane-soluble part of the reaction mixture). The number-average molecular weight $\left(M_{\mathrm{n}}\right)$ of $\mathbf{7 a}$ was estimated as 28600 (GPC, polystylene standard) which was also very close to that of starting polymer. The polymer (7a) was soluble in organic solvents such as chloroform, toluene and THF.

The structure of 7a was confirmed by ${ }^{1} \mathrm{H}$ and ${ }^{31} \mathrm{P}$ NMR spectra. In the ${ }^{1} \mathrm{H}$ NMR spectrum of $\mathbf{7 a}$, the content of the organocobalt moieties bearing tri-n-

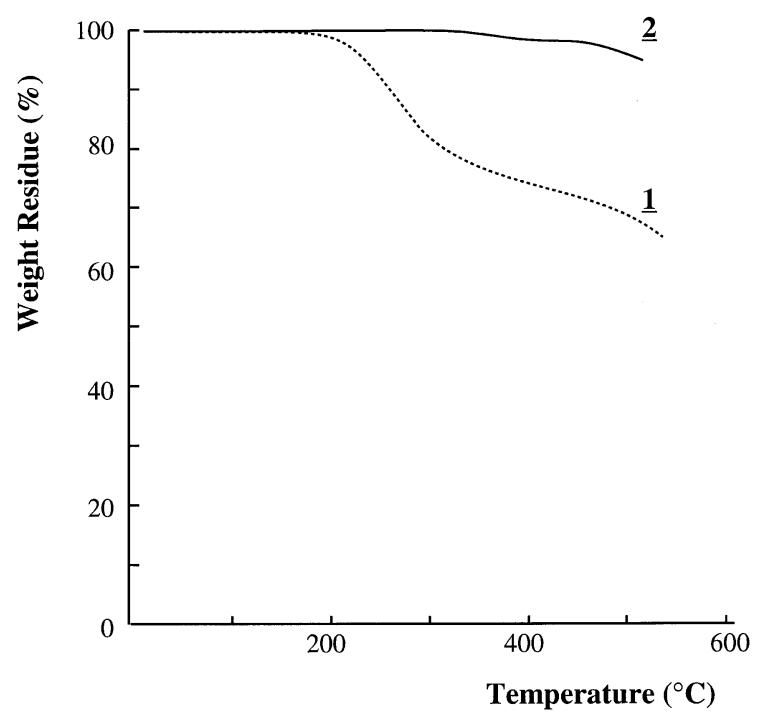

Figure 2 Thermogravimetric analyses (TGA) of $\mathbf{1}$ and $\mathbf{2}$ under nitrogen $\left(10^{\circ} \mathrm{C} / \mathrm{min}\right.$.).

(C) 1998 John Wiley \& Sons, Ltd.
Table 2 Reactions of $\mathbf{3}$ with $\mathbf{5} \mathbf{a}^{\mathrm{a}}$

\begin{tabular}{|c|c|c|c|}
\hline \multirow[b]{2}{*}{ Run } & \multirow{2}{*}{$\begin{array}{c}\text { Ratio, 5a : } \mathbf{3} \\
\text { (equiv./equiv.) }\end{array}$} & \multicolumn{2}{|c|}{ Yield $(\%)^{\mathrm{b}}$} \\
\hline & & $6 \mathbf{6}$ & 4 \\
\hline 1 & 1 & 64 & 33 \\
\hline 2 & 10 & 92 & Trace \\
\hline
\end{tabular}

butylphosphine in the polymer 7a obtained was estimated as almost quantitative $(>96 \%)$ on the basis of the integral ratio between multiple peaks at 0.46-2.12 ppm attributable to the n-butyl groups and a peak at $4.67 \mathrm{ppm}$ for the cyclopentadienyl groups (Fig. 3). This result is consistent with the experiment using a model compound (3). While the ${ }^{31} \mathrm{P}$ NMR spectrum of 1 showed a peak for $\mathrm{Co}-\mathrm{PPh}_{3}$ at $50.9 \mathrm{ppm}$, only one peak was observed at $33.9 \mathrm{ppm}$ attributable to the $\mathrm{Co}-\mathrm{P}(\mathrm{n}-\mathrm{Bu})_{3}$ moieties in the case of 7a (Fig. 4).

As summarized in Table 3 , the ratio of the displaced unit and the cyclobutadienecobalt moieties in the polymer could be controlled by the feed ratio of 5:1. The reaction with tri-n-octylphosphine (5b) also produced the corresponding polymer (7b) that contained tri-n-octylphosphine quantitatively as a ligand. However, the reaction with tricyclohexylphosphine (5c) did not give the desired polymer, probably due to the steric hindrance (large cone angle) in 5c. [In the presence of 5c, the conversion of the cobaltacyclopentadiene moieties to the cyclobutadienecobalt units was suppressed. This result might indicate that the coordinatively unsaturated cobalt atom binds $\mathbf{5 c}$ in the course of the reaction.]

Although, polymers $\mathbf{7 a}$ and $\mathbf{7 b}$ may have somewhat improved thermal stability in comparison with $\mathbf{1}$, no significant change in TGA or in DSC was observed, i.e. the weight loss of $\mathbf{7 a}$ in TGA started at $195^{\circ} \mathrm{C}$, similarly to the case of $1\left(197^{\circ} \mathrm{C}\right)$, and no peaks were found below the decomposition in DSC measurements. However, the solubility of 7 differed from that of $\mathbf{1}$, e.g. $\mathbf{7 b}$ is soluble even in $\mathrm{n}$ hexane, which is a poor solvent for $\mathbf{1}$.

\section{EXPERIMENTAL}

\section{Materials and instruments}

The organocobalt polymer (1) was prepared as 


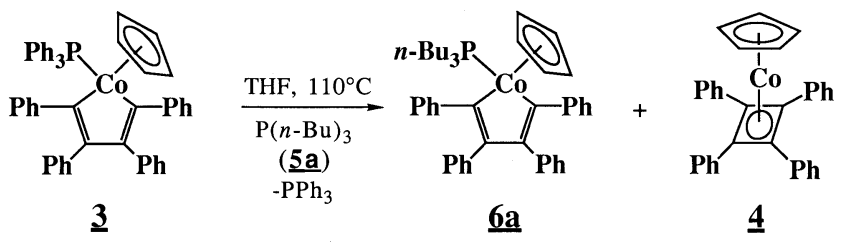

Scheme 5
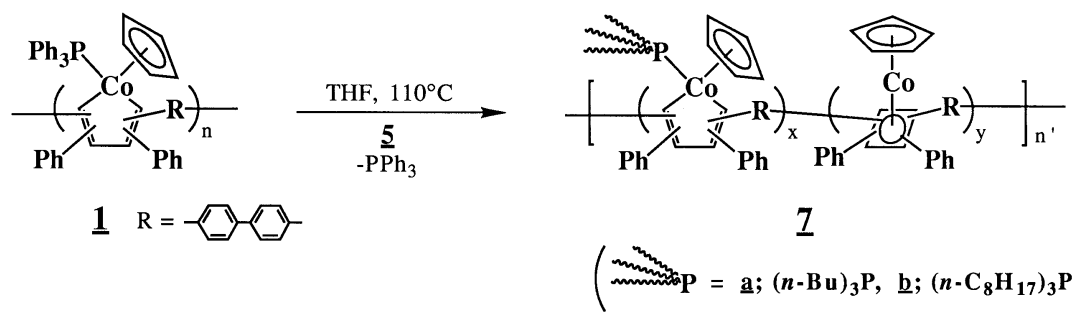

Scheme 6

previously described by using isolated crystals of $\left(\eta{ }^{5}\right.$-cyclopentadienyl)bis(triphenylphosphine)cobalt with 4,4'-bis(phenylethynyl)biphenyl, and was isolated by precipitation with n-hexane. ${ }^{2,3}$ Phosphines $\mathbf{5 a}$ and $\mathbf{5 b}$ were distilled before use. Tricyclohexylphosphine (5c, 25\% in toluene) was obtained from Kanto Chemical Co. and was used as received. THF was dried over sodium and was distilled under nitrogen. All the other reagents were used as received.

${ }^{1} \mathrm{H}$ and ${ }^{13} \mathrm{C}$ NMR spectra in $\mathrm{CDCl}_{3}$ were recorded on a JEOL EX-90 instrument (90 and $22.5 \mathrm{MHz}$ for ${ }^{1} \mathrm{H}$ and ${ }^{13} \mathrm{C} \mathrm{NMR}$, respectively; tetramethylsilane as an internal standard). ${ }^{31} \mathrm{P}$ NMR spectra in a mixed solution of toluene and $\mathrm{C}_{6} \mathrm{D}_{6}$

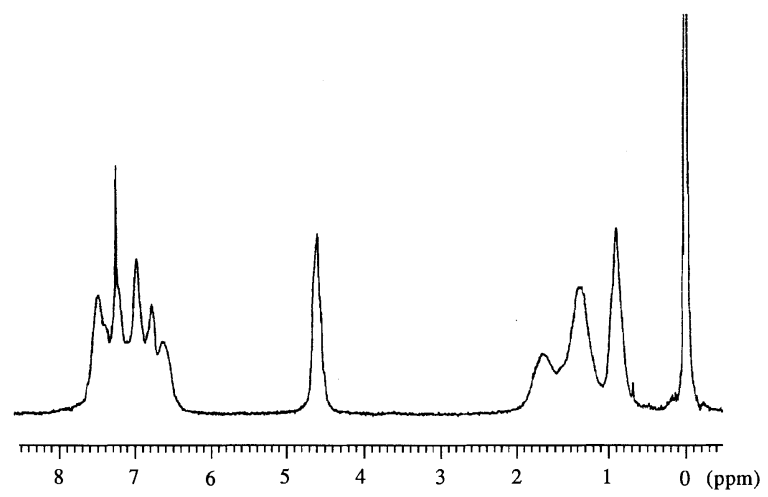

Figure $3{ }^{1} \mathrm{H}$ NMR spectrum $\left(90 \mathrm{MHz}\right.$, in $\left.\mathrm{CDCl}_{3}\right)$ of $\mathbf{7 a}$. were recorded on a JEOL FX-100 instrument (40.5 MHz; $80 \%$ aqueous phosphoric acid as an external standard). IR spectra were obtained on a JASCO FT/IR-5300 spectrometer. Gel-permeation chromatographic (GPC) analyses were carried out on a Tosoh CCPD (TSK gel G4000HXL; THF as an eluent) on the basis of standard polystyrene samples. TGA measurements were carried out on a Seiko TG/DTA 220 instrument at a heating rate of $10{ }^{\circ} \mathrm{C} \mathrm{min}{ }^{-1}$ under nitrogen. DSC analysis was performed on a Seiko DSC 220C at a heating rate of $5^{\circ} \mathrm{C} \mathrm{min}{ }^{-1}$.

\section{Synthesis of 2 by the rearrangement of 1}

In a degassed sealed tube, a THF (10 ml) solution of 1 (0.048 g, $0.065 \mathrm{mmol}$ unit) was heated for $1 \mathrm{~h}$. The resulting greenish yellow solution was poured into $\mathrm{n}$-hexane $(100 \mathrm{ml})$, and the precipitate was dried under vacuum. A yellow powdery polymer (2) was obtained in $79 \%$ yield $(0.025 \mathrm{~g}$, $0.051 \mathrm{mmol})$ : The ${ }^{1} \mathrm{H}$ NMR spectrum is shown in Fig. 1(b); ${ }^{13} \mathrm{C} \mathrm{NMR}\left(\mathrm{CDCl}_{3}, \delta\right) 83.29,126.1-129.2$, 135.7-138.2 ppm; IR (KBr) 3055, 3026, 1599, 1442, 1219, 1180, 1109, 1003, 810, 750, 590, $567 \mathrm{~cm}^{-1}$.

Appl. Organometal. Chem. 12, 735-742 (1998) 

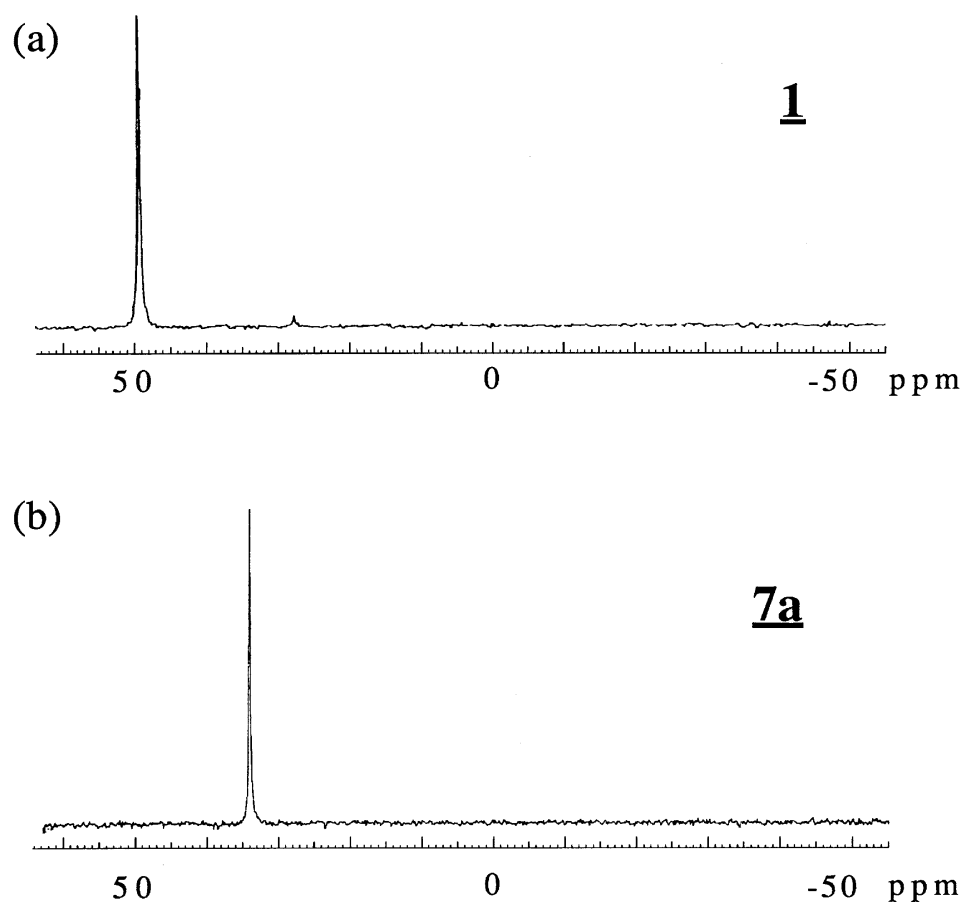

Figure $4{ }^{31} \mathrm{P}$ NMR spectra (40.5 MHz, in $\mathrm{C}_{6} \mathrm{D}_{6} /$ toluene) of $\mathbf{1}$ (a) and $\mathbf{7 a}(\mathrm{b})$.

\section{Rearrangement reaction of a model compound (3)}

A THF ( $5 \mathrm{ml})$ solution of $\mathbf{3}(0.14 \mathrm{~g}, 0.19 \mathrm{mmol})$ was heated at $110^{\circ} \mathrm{C}$ for $1 \mathrm{~h}$ in a degassed sealed tube. After the reaction, the product (4) was isolated by column chromatography on neutral $\mathrm{Al}_{2} \mathrm{O}_{3}$ (nhexane $)$ in $97 \%$ yield $(0.088 \mathrm{~g}, 0.18 \mathrm{mmol}) .4$ : ${ }^{13} \mathrm{C}$ NMR $\left(\mathrm{CDCl}_{3}, \delta\right) 83.24,126.14,128.00$,
129.16, $136.47 \mathrm{ppm}$; IR (KBr) 3055, 2962, 1595, $1496,1442,1261,1095,1022,802,742,700,590$, $567 \mathrm{~cm}^{-1}$; the ${ }^{1} \mathrm{H}$ NMR spectrum is shown in Figure 1(c).

\section{A Model Reaction of $\mathbf{3}$ with $\mathbf{5 a}$}

A THF (7 ml) solution of $\mathbf{3}(0.11 \mathrm{~g}, 0.15 \mathrm{mmol})$ and 5a $(0.23 \mathrm{~g}, 1.13 \mathrm{mmol})$ was heated at $110^{\circ} \mathrm{C}$ for $1 \mathrm{~h}$

Table 3 Reactions of organocobalt polymer $\mathbf{1}$ with trialkylphosphines $\mathbf{5 a}-\mathbf{5} \mathbf{c}^{\mathrm{a}}$

\begin{tabular}{|c|c|c|c|c|}
\hline Run & Phosphine & Ratio, 5:1 & Ratio, $\mathbf{x}: \mathbf{y}^{\mathrm{b}}$ & Isolated yield $(\%)$ \\
\hline 1 & $\mathrm{P}\left(\mathrm{n}-\mathrm{C}_{4} \mathrm{H}_{9}\right)_{3}(\mathbf{5 a})$ & 1 & $71: 29$ & $88^{\mathrm{d}}$ \\
\hline 2 & & 10 & $100: 0$ & $94^{\mathrm{d}}$ \\
\hline 3 & $\mathrm{P}\left(\mathrm{n}-\mathrm{C}_{8} \mathrm{H}_{17}\right)_{3}(\mathbf{5 b})$ & 1 & $61: 39$ & $92^{\mathrm{e}}$ \\
\hline 4 & & 10 & $100: 0$ & $100^{\mathrm{e}}$ \\
\hline 5 & D) $(5 c)$ & 1 & $0: 66^{\mathrm{c}}$ & - \\
\hline
\end{tabular}

\footnotetext{
${ }^{\text {a }}$ Reactions were carried out in $\mathrm{THF}$ at $110^{\circ} \mathrm{C}$ for $1 \mathrm{~h}$ in a degassed sealed tube.

${ }^{\mathrm{b}}$ Determined by ${ }^{1} \mathrm{H}$ and ${ }^{31} \mathrm{P}$ NMR $(x=$ metallacyclopentadiene unit, $y=$ cyclobutadiene unit $)$.

c The product contained $34 \%$ of the starting unit.

d n-Hexane-insoluble part.

e Methanol-insoluble part.
} 
in a degassed sealed tube. After the reaction, 6a was isolated by column chromatography on neutral $\mathrm{Al}_{2} \mathrm{O}_{3}$ (n-hexane benzene $=15: 1-1: 1$ ) in $92 \%$ yield $(0.093 \mathrm{~g}, 0.14 \mathrm{mmol}) .6 \mathrm{a:}{ }^{1} \mathrm{H} \mathrm{NMR}\left(\mathrm{CDCl}_{3},\right)$ 0.50$2.02\left(\mathrm{~m}, \mathrm{P}_{-} \mathrm{C}_{4} \mathrm{H}_{9}, 27 H\right), 4.59\left(\mathrm{~s}, \mathrm{C}_{5} \mathrm{H}_{5}, 5 H\right), 6.30-$ $7.30 \mathrm{ppm}\left(\mathrm{m}, \mathrm{C}_{6} \mathrm{H}_{5}, 20 H\right) ;{ }^{13} \mathrm{C} \mathrm{NMR}\left(\mathrm{CDCl}_{3}, \delta\right)$ 24.26, 24.80, 25.89, 26.99, 27.10, 87.91, 123.04, $123.52,126.23,126.68,128.81,130.50,142.09$, 153.85 ppm; IR (KBr) 3055, 3022, 2957, 2928, 1593, 1479, 1464, 1439, 1379, 1091, 908, 806, 725, $698,626,533 \mathrm{~cm}^{-1}$.

\section{Reactions of 1 with trialkylphosphines (5a 5b)}

As a typical run, the reaction of $\mathbf{1}$ with $\mathbf{5 a}$ (Table 3, run 2) was carried out as follows. In a degassed sealed tube, $1(0.050 \mathrm{~g}, 0.067 \mathrm{mmol})$ and 5a $(0.141 \mathrm{~g}, 0.70 \mathrm{mmol}, 10$ equiv. $)$ in $\mathrm{THF}(3.5 \mathrm{ml})$ was heated at $110{ }^{\circ} \mathrm{C}$ for $1 \mathrm{~h}$. After the reaction, the mixture was poured into n-hexane $(100 \mathrm{ml})$ to precipitate the product (7a) in $94 \%$ yield $(0.043 \mathrm{~g}$, $0.063 \mathrm{mmol}) .{ }^{1} \mathrm{H}$ and ${ }^{31} \mathrm{P}$ NMR are shown in Figs 3 and 4, respectively. IR (neat) 3055, 3022, 2957, 2930, 2870, 1597, 1481, 1379, 1179, 1091, 1005, $909,810,733,700 \mathrm{~cm}^{-1}$.

Similarly, 7b (Table 3, run 4) was isolated in $100 \%$ yield $(0.078 \mathrm{~g}, 0.092 \mathrm{mmol})$ by precipitation with methanol after the reaction of $1(0.068 \mathrm{~g}$, $0.092 \mathrm{mmol})$ with $\mathbf{5 b}(0.343 \mathrm{~g}, 0.925 \mathrm{mmol}) .{ }^{1} \mathrm{H}$ NMR $(\delta)$ 0.64-2.68 $\left(-\mathrm{C}_{8} \mathrm{H}_{17}\right), 4.68\left(\mathrm{C}_{5} \mathrm{H}_{5}\right.$, br s), 6.38-7.78 ppm $\left(\mathrm{C}_{6} \mathrm{H}_{5}, \mathrm{C}_{6} \mathrm{H}_{4}\right)$ [the integral ratio of the peak of $\mathrm{P}\left(\mathrm{C}_{8} \mathrm{H}_{17}\right)_{3}$ to that of $\mathrm{C}_{5} \mathrm{H}_{5}$ was 51:5.0, from which the content of the displaced unit was estimated as 100\%]; IR (neat) 3056, 3022, 2955 , 2924, 2854, 1597, 1481, 1466, 1377, 1261, 1070, $1005,808,747,700 \mathrm{~cm}^{-1}$.

Acknowledgment This work was supported by the Grant-inAid for Scientific Research on the Priority Area of Reactive Organometallics No 05236104 from the Ministry of Education, Science and Culture, Japan.

\section{REFERENCES}

1. Macromolecules, 27, 7009 (1994).

2. I. Tomita, A. Nishio, T. Igarashi and T. Endo, Polym. Bull. 30, 179 (1993).

3. I. L. Rozhanskii, I. Tomita and T. Endo, Macromolecules 29, 1934 (1996).

4. A. Ohkubo, K. Aramaki and H. Nishihara, Chem. Lett. 271 (1993).

5. M. Altmann and U. H. F. Bunz, Macromol. Rapid Commun. 15, 785 (1994).

6. M. Altmann and U. H. F. Bunz, Angew. Chem., Int. Ed. Engl. 34, 569 (1995).

7. S. S. H. Mao and T. D. Tilley, J. Am. Chem. Soc. 117, 5365 (1995).

8. I. Tomita, A. Nishio and T. Endo, Macromolecules 28, 3042 (1995).

9. H. Yamazaki and N. Hagihara, J. Organometal. Chem. 7, P22 (1967).

10. M. D. Rausch and R. A. Genetti, J. Org. Chem. 35, 3888 (1970).

11. K. Yasufuku, A. Hamada, K. Aoki and H. Yamazaki, J. Am. Chem. Soc. 102, 4363 (1980). 